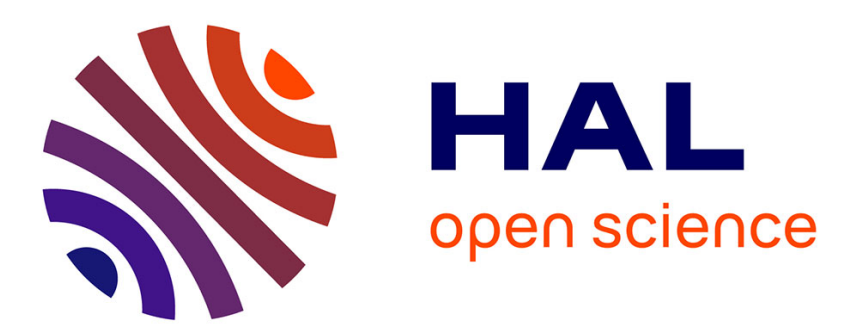

\title{
Pollution and growth: The role of pension in the efficiency of health and environmental policies
}

Armel Ngami, Thomas Seegmuller

\section{To cite this version:}

Armel Ngami, Thomas Seegmuller. Pollution and growth: The role of pension in the efficiency of health and environmental policies. International Journal of Economic Theory, 2021, 17 (4), pp.390415. 10.1111/ijet.12247 . hal-02428909

\section{HAL Id: hal-02428909 \\ https://hal-amu.archives-ouvertes.fr/hal-02428909}

Submitted on 3 Jan 2022

HAL is a multi-disciplinary open access archive for the deposit and dissemination of scientific research documents, whether they are published or not. The documents may come from teaching and research institutions in France or abroad, or from public or private research centers.
L'archive ouverte pluridisciplinaire HAL, est destinée au dépôt et à la diffusion de documents scientifiques de niveau recherche, publiés ou non, émanant des établissements d'enseignement et de recherche français ou étrangers, des laboratoires publics ou privés. 


\title{
Pollution and growth: The role of pension on the efficiency of health and environmental policies*
}

\author{
By Armel Ngami ${ }^{\dagger}$, Thomas Seegmuller ${ }^{\ddagger}$
}

\begin{abstract}
This paper analyses the effect of a pay-as-you-go pension system on the evolution of capital and pollution, and on the efficiency of an environmental versus health policy. In an overlapping generations model (OLG), we introduce endogenous longevity that depends on pollution and health expenditures. Global dynamics may display multiple balanced growth paths (BGP). We show that by discouraging savings, a policy that promotes the pension system enlarges the environmental poverty trap. More surprisingly, the environmental policy has contrasted effects according to the significance of the pension system. If it has a low size, a raise of the environmental policy enlarges the environmental poverty trap and leads to a rise in capital over pollution at the highest stationary equilibrium. In contrast, in economies where intergenerational solidarity is well developed, capital over pollution decreases at the highest BGP. In such a case, the environmental policy does not necessarily lead to a better longevity and growth.
\end{abstract}

\section{JEL Classification I15; O44; Q56}

Keywords Longevity, Environment, Health, Pension System, Endogenous Growth, Pollution.

\footnotetext{
${ }^{*}$ We would like to thank an associated editor and an anonymous referee for their remarks that helped to greatly improve the paper. We also thank Frédéric Dufourt and Hubert Stahn for their helpful comments, and the French National Research Agency for their financial support (ANR-15-CE33-0001-01 and ANR-16-CE030005). This paper has also benefited from the comments of the participants at the conferences LAGV 2019 Aix-en-Provence, ASSET 2018 Florence (Italy), DMM 2018 Montpellier, FAERE 2018 Aix-en-Provence and at the Green-Econ 2017 Workshop in Aix-en-Provence.

${ }^{\dagger}$ Corresponding author.

Aix-Marseille University, CNRS, EHESS, Centrale Marseille, AMSE

5-9 Boulevard Bourdet, CS 50498, 13205 Marseille Cedex 1, France

e-mail: armel.ngami@univ-amu.fr

${ }^{\ddagger}$ Aix-Marseille University, CNRS, EHESS, Centrale Marseille, AMSE

5-9 Boulevard Bourdet, CS 50498, 13205 Marseille Cedex 1, France

e-mail: thomas.seegmuller@univ-amu.fr
} 


\section{Introduction}

As it can be seen in the abundant related literature, the rationale that lies behind the existence of a positive relationship between individuals' health status, especially their life expectancy, and the economic development is quite intuitive. A worker in good health may have a higher productivity and is less often on sick leave. This has a positive impact on economic growth. Similarly, healthier people are more likely to accumulate human or physical capital because they hope to be alive longer enough to enjoy the future benefits of their investments. Therefore, by stimulating the capital accrual, longevity improvements has a positive impact on economic development. This could justify the healthcare expenditures upward trend observed for OECD countries. From $2.5 \%$ in 1970, they account for $6 \%$ of the GDP on average in 2010 (Marino et al., 2017) and projections give them around 9.5\% in 2060 (De La Maisonneuve and Martins, 2013). On the other hand, economic growth is associated with more tax revenues for the government, and this implies more funds to build health facilities, to finance medical research, and broadly better health services. Hence, higher longevity and economic development mutually reinforce each other. This channel is well depicted in Acemoglu and Jonhson (2007), Blackburn and Cipriani (2002), Cervelatti and Sunde (2005), Chakraborty (2004), Chakraborty and Das (2005), Zhang and Zhang (2005).

However, economic development goes along with the production of wastes, which might be harmful for human health/longevity (Van Oort et al., 2007). According to Landrigan et al. (2017), pollution was responsible of 1 over 6 deaths around the world in 2015, and that represents 9 million premature deaths during that period. It is three times more than deaths attributed to AIDS, tuberculosis and malaria combined. This echoes Evans and Smith (2005)'s findings that stress on the negative role played by exposure to particulate matter in the onset of serious health conditions in US. Similarly, the unprecedented economic growth experienced by China at the beginning of this century was accompanied by modest life expectancy improvements with respect to neighboring countries longevity gains, due to environmental degradation (Ebenstein et al., 2015). During that period, an increase of $100 \mu / \mathrm{m}^{3}$ of particulate matter concentration in the air was associated with a fall of 1.5 year of the life expectancy at birth in that country.

At the same time, the population ageing is under way and by 2050, there will have more seniors than children on earth (Balestra and Dottori, 2012). Against a backdrop where people live longer, a pension system is an important channel to finance the standard of living of people once retired. In several european countries, there exists a public pension system, more or less developed. As we can see in Table 1, the contribution rate to the public pension system can reach one third of gross earnings in some countries and it is around $20 \%$ in average in OECD countries. However, there is more and more evidence that pension systems, especially pay-as-you-go (PAYG) ones, have a negative impact on individual savings (Attanasio and Rohwedder, 2003). 
Although the question of their financing remains essential, not much has been done in the literature to understand how public pension systems might affect the efficiency of other policy instruments such as health or environmental policies. In the meantime, there is no consensus in the literature on the efficiency of health policies in accelerating economic growth. For instance, Barro and Sala-i-Martin (1995) suggest that improving health outcomes contributes positively to the economic growth whereas Acemoglu and Johnson (2007) find no effect at all.

This paper presents a simple framework to analyse how a PAYG pension system, by distorting saving, could modify the effects of environmental and health policies on the long run equilibrium. ${ }^{1}$ It relies on an overlapping generations model (OLG) with endogenous saving rate and longevity. In addition, because health services and pollution abatements activities both lead to a lifespan extension, health and environmental policies compete for resources allocation.

PAYG pension systems are grounded on the principle that workers contributions finance seniors pensions. Therefore, people save less because they rely on the government to finance their old-age standard of living. By diverting resources away from the financial market, PAYG schemes dampen the capital accumulation. This is the point raised by Attanasio and Rohwedder (2003) and Attanasio and Brugiavini (2003) when studying pension system reforms in Italy and UK that occurred at the end of the last century. They found that the earning related part of the pension scheme has a negative impact on private saving. The higher it

\begin{tabular}{|l|l|}
\hline France & 16.7 \\
\hline Greece & 20.0 \\
\hline Spain & 28.3 \\
\hline EU27 & $\mathbf{2 2 . 6}$ \\
\hline USA & 10.4 \\
\hline Japan & 28.0 \\
\hline Brazil & 31.0 \\
\hline China & 28.0 \\
\hline OECD & $\mathbf{1 9 . 6}$ \\
\hline
\end{tabular}
is, the less people put money aside for their old earnings) (OECD, 2013) age.

In addition to that, a strong relationship between the provision of a pension and people health has been exhibited in the literature. For instance, Lundberg et al. (2008) has found that a generosity in basic security pension is associated with a reduction of old-age mortality for both sexes in 18 OECD countries. At a micro-level, Case (2004) argue that by improving living conditions and the nutritional status of household members, the pension paid to seniors in South Africa could protect everyone health in the household. Similarly, through a nonparametric estimation, Duflo (2000) concludes to the same positive impact of pension in South Africa on health and nutrition of children.

\footnotetext{
${ }^{1}$ It is worth mentioning that we rule out the case of fully funded pension systems, because they do not entail any intergenerational effect and they are also neutral to capital accumulation.
} 
This paper precisely aims at studying the impact of a pension system on the efficiency of environmental and health policies in affecting the long run dynamics of capital, pollution and consequently of the life expectancy. In our framework, households live at most for 2 periods, a working one and the retirement. Although they are all alive during the whole first period, they just live a share of the second period. When young, they consume and save their labor income, but when old, their consumption is funded by pension and remunerated saving. The public authorities managed two balanced budgets funded by labor taxes. The first one is shared between health expenditures and pollution abatement activities. They are the determinants that drive household length-of-life at older ages. However, while healthcare directly improves life expectancy, cleaning activities do the same by hampering the environment degradation. The second budget is devoted to a pay-as-you-go public pension system.

Focusing on the dynamics of pollution and capital and the way public policies, especially pension system, shape the long run equilibrium, we find, as expected, that a policy that fosters intergenerational solidarity enlarges the environmental poverty trap and reduces the level of capital over pollution at the higher steady-state. This is due to the fact that the provision of a pension acts as a disincentive to save. The environmental poverty trap is the situation in which the wealth an economy generates is low compared to the stock of pollution that goes along with the production activity. ${ }^{2}$ In such a case, the ratio of capital over pollution decreases over the time and converges to 0 . On the contrary, the effect of the environmental policy depends on the level of development of the country. Indeed, a poor country, that would have converged to the stable steady state, may fall into the environmental poverty trap following a rise in the share of environmental policy in the budget. Meanwhile, a rich country may converge to a higher level of capital over pollution following the same policy. This discrepancy is due to the concavity of the longevity function. Nonetheless, for a developed country where the share of the gross earning that finances the pension system is already high, the environmental policy has a reverse effect on the long run dynamics, that is, the economy converges to a balanced growth path with a lower ratio of capital over pollution. Indeed, the bigger the pension system is, the greater the marginal effect of the environmental/health policy will be. Such a policy induces two conflicting effects, one on the saving rate and the longevity, and the other on the pollution. A greater intergenerational solidarity tends to favor the first one with respect to the second.

To summarize, our main contribution lies in the analysis of the joint effect of environmental and pension policies, in an OLG framework with endogenous longevity. We show that for a rich country, the environmental policy does not necessarily lead to a better longevity and growth, especially when the intergenerational solidarity is well developed. Quite the contrary, it increases the size of the poverty trap and reduces the ratio of capital over pollution

\footnotetext{
${ }^{2}$ Throughout this paper, we may use the expresion poverty trap to mention the environmental poverty trap.
} 
at the stable steady state when the size of the pension system is above a threshold.

The outlines of the paper are the following: in Section 2, we will present the framework of this paper and in Section 3, we define the conditions that prevail at the intertemporal equilibrium. In Section 4, we analyse the properties of the long run equilibria and in Section 5, we discuss of the effect of economic policies on the long run dynamics. Section 6 concludes, whereas technical details are relegated to an Appendix.

\section{Model}

This section presents economic agents in our framework and the main features of the model. In particular, it defines the government sphere of activities and what we understand by environmental degradation.

\subsection{Households}

We consider an overlapping generation model (OLG) with discrete time, indexed by $t=$ $0,1, \cdots,+\infty$. Agents live for two periods, an active one and the retirement. The length of both periods is 1 . When young, individuals live the entire period and supply their labor force to produce the unique good of the economy. The number of workers at each period is constant and is normalised to 1 . In return, they receive a wage $\omega_{t}$ they use for consumption $\left(c_{t}\right)$ and for saving $\left(s_{t}\right)$. However, an household just lives a length $\phi_{t}\left(0 \leq \phi_{t} \leq 1\right)$ when old, a timespan during which he uses his remunerated savings ( at a per unit rental price of $\left.r_{t+1}\right)$ and the pension paid by the government $\left(z_{t+1}\right)$ for his retirement consumption $\left(d_{t+1}\right)$. Let us also mention that if the second period of time is indivisible, $\phi_{t}$ can be interpreted as the probability the household lives the second period. Alternatively, $\phi_{t}$ captures the life expectancy or longevity in our model. The preference of the household is given by the following utility function: ${ }^{3}$

$$
U_{t}=\ln c_{t}+\phi_{t} \ln d_{t+1}
$$

In our framework, the longevity is endogenous as in Chakraborty (2004). It depends of the health status $\varepsilon_{t}$ of the agent represented by the ratio of health expenditures $\left(H_{t}\right)$ over the level of pollution $\left(P_{t}\right)$. The former is beneficial for health while pollution is noxious to it. This is consistent with the findings of several empirical studies. Ebenstein et al. (2005) shows that an increase of particles' concentration of $100 \mu g$ per meter-cube is associated with a decrease of 2.3 years of the life expectancy at 5 years old. Similarly, the WHO has assessed in 2006 that air pollution is responsible of a decrease of 8.6 months in average of life expectancy in Europe.

By the way, the function $\phi_{t}$ satisfies the usual properties of endogenous life expectancy

\footnotetext{
${ }^{3}$ As Chakraborty(2004), Varvarigos (2010) and Raffin and Seegmuller (2014)
} 
which are $\phi(0)=0, \phi(\infty)=b \leq 1, \phi^{\prime}(0)<\infty, \phi^{\prime}>0, \phi^{\prime}(\infty)=0, \phi^{\prime \prime}<0$. Therefore, the life expectancy can be written as follows: ${ }^{4}$

$$
\phi_{t} \equiv \phi\left(\varepsilon_{t}\right)=\frac{b \varepsilon_{t}}{1+\varepsilon_{t}} \text { with } \varepsilon_{t} \equiv \frac{H_{t}}{P_{t}}
$$

The longevity is increasing and concave with the health status $\varepsilon_{t}$. This means that a change in the health expenditure has a greater impact on life expectancy when the health status is low, and a more limited one otherwise. This can explain the little gain in longevity in western countries despite huge investments in health whereas less developed ones have experienced a huge increase in longevity (See the WHO report, 2003). This phenomenon is represented here by the parameter $b$. The higher the latter, the more concave $\phi_{t}$ is; that is, the more sensitive to lower values of health status the longevity is. In addition, life expectancy is nil when there is no health expenditure. Finally, let us notice that longevity is upper bounded and is quite constant when the health status is already high.

As aforementioned, a household uses his available income to buy goods and to save the remaining. Furthermore, we assume a perfect annuity market. The financial intermediaries do not obtain any benefit from their activities and therefore, they gives back to the survivor households all the money they have collected. It implies that the effective interest rate on savings is equal to $\frac{r_{t+1}}{\phi_{t}}$. Hence, the budget constraints faced by a household are:

$$
\left\{\begin{array}{c}
c_{t}+s_{t}=\left(1-\tau_{1}-\tau_{2}\right) \omega_{t} \\
d_{t+1}=\frac{r_{t+1} s_{t}}{\phi_{t}}+z_{t+\mathbf{1}}
\end{array}\right.
$$

The first equation expresses the traditional trade-off a household has to cope with between consumption and savings. Nonetheless, this trade-off is weakened here by the pension system $\left(z_{t+1}\right)$ that may act like a disincentive for saving by financing a share of old age consumption. The budget constraint over the life span is $c_{t}+\frac{\phi_{t}}{r_{t+1}} d_{t+1}=\left(1-\tau_{1}-\tau_{2}\right) \omega_{t}+$ $\frac{\phi_{t}}{r_{t+1}} z_{t+1}$. In this equation, the available income when young is $\left(1-\tau_{1}-\tau_{2}\right) \omega_{t}$ as the government levies taxes $\tau_{1}$ and $\tau_{2}$ to finance respectively on the one hand the environmental and health policies and on the other the pension system.

\footnotetext{
${ }^{4}$ see Blackburn and Cipriani (2002), Chakraborty(2004), Constant (2015), Raffin and Seegmuller (2014) and Varvarigos (2010)
} 
The optimal microeconomic choices of an agent born at the period $t$ are the following:

$$
\begin{aligned}
c_{t} & =\frac{\left(1-\tau_{1}-\tau_{2}\right) \omega_{t}}{1+\phi_{t}}+\frac{\phi_{t}}{1+\phi_{t}} \frac{z_{t+1}}{r_{t+1}} \\
d_{t+1} & =r_{t+1} \frac{\left(1-\tau_{1}-\tau_{2}\right) \omega_{t}}{1+\phi_{t}}+\frac{\phi_{t}}{1+\phi_{t}} z_{t+1} \\
s_{t} & =\left(1-\tau_{1}-\tau_{2}\right) \omega_{t}-c_{t}=\frac{\phi_{t}}{1+\phi_{t}}\left(\left(1-\tau_{1}-\tau_{2}\right) \omega_{t}-\frac{z_{t+1}}{r_{t+1}}\right)
\end{aligned}
$$

As expected, consumptions at each period are proportional to the lifetime income.

\subsection{Firms}

The unique final good in the economy, which can also be used as capital good, is produced by perfectly competitive firms that combines labor offered by young and capital from financial intermediaries using the following technology: $Y_{t}=F\left(K_{t}, \bar{K}_{t} L_{t}\right)=A K_{t}^{\alpha}\left(\bar{K}_{t} L_{t}\right)^{1-\alpha}$ with $A>0$ and $0<\alpha<1$. $Y_{t}$ is the aggregate output, $K_{t}$ the aggregate level of capital and $L_{t}$ the aggregate labor. $\bar{K}_{t}$ is the average level of capital in the economy and is considered as given by firms. This means the labor productivity increases with capital through for example, a learning by doing process. It will be the vector of endogenous growth. In addition, we assume that capital is fully depreciated after one period of use. ${ }^{5}$

With $\omega_{t}$ and $r_{t}$ denoting respectively the real wage and the real interest rate, the optimal choices for the firms are described by:

$$
\begin{gathered}
\omega_{t}=(1-\alpha) A \bar{K}_{t}^{1-\alpha}\left(\frac{K_{t}}{L_{t}}\right)^{\alpha} \\
r_{t}=\alpha A K_{t}^{\alpha-1}\left(\bar{K}_{t} L_{t}\right)^{1-\alpha}
\end{gathered}
$$

\subsection{Government}

In our setup, the government budget is balanced and is financed by imposing a proportional $\operatorname{tax} \tau_{1}+\tau_{2}\left(0<\tau_{1}+\tau_{2}<1\right)$ on wages households receive from firms. With that revenue, public authorities provide 3 kinds of services:

- Public health care denoted $H_{t}$. This encompasses the cost of building new hospital, prevention campaigns, the budget of medical research, etc. Curative health services represent a labor income tax of $\mu \tau_{1}$. Therefore, the public health expenditures account for $H_{t}=\mu \tau_{1} \omega_{t} L_{t}$ with $0<\mu<1 .^{6}$

\footnotetext{
${ }^{5}$ We consider a model with endogenous rather than exogenous growth to have more tractable expressions and be able to discuss the effect of policies on the growth factor.

${ }^{6}$ This condition, along with the strictly positivity of the stock of capital, rules out the case of a zero lengthof-life. This happens when there is no public health care provided.
} 
- Pollution abatement activities denoted $G_{t}$. This incorporates the cost of all public environmental maintenance activities, which includes the domestic garbage collection, the maintenance of green areas which improve the air quality and so on. We also include all recycling activities of industrial wastes. This represents a labor income tax of $(1-\mu) \tau_{1}$ and therefore environmental policy is endowed with a budget of $G_{t}=(1-\mu) \tau_{1} \omega_{t} L_{t}$.

- The payment of a retirement pension, to all retired households still alive. The amount paid is function of the number of workers, their wages, and also of the level of mortality. The budget of the pension system represents a proportion $\tau_{2}$ of the total public budget, that is $\tau_{2} \omega_{t} L_{t}$.

It is noteworthy that we are in a pay-as-you-go pension system setup and agents completely rely on government for their retirement pension. This creates incentives to save less (because they expect a helping hand from government when old) and consequently, it could adversely affect the capital accumulation. ${ }^{7}$

In addition, we have to mention that there is no individual health care expenditures and the life expectancy depends only on public health care and pollution when young. Actually, the public budget is divided into two independent poles (or sub-budgets), the health and environmental one financed by a tax $\tau_{1}$ and the pension system funded with the tax $\tau_{2}$. However, within the first sub-budget, there is a budgetary trade-off between supporting health care expenditures or financing more pollution abatement activities. This trade-off, represented by the parameter $\mu$, seems justified because both are longevity enhancing policies.

However, these policies do not act in the same way on the household life expectancy. One could consider that the health policy encompasses all curative measures, whereas pollution abatement activities could be assimilated to preventive ones. In addition, in the case there is no health measures, that is $\mu=0$, all households are dead at the end of the working period, there are no savings, and the equilibrium will collapse to zero capital accumulation. On the contrary, having no environmental expenses $(\mu=1)$ does not prevent from having a strictly positive survival probability and all the mechanisms described in the following sections hold. We choose to take into account both public health expenditures and the environmental quality as the government budget comprises both curative and preventive health measures.

As aforementioned, retirement pensions depends on labor market features and on mortality. Furthermore, we assume the pension system is balanced, that means $\tau_{2} \omega_{t} L_{t}=z_{t} \phi_{t-1} L_{t-1}$.

\footnotetext{
${ }^{7}$ On the contrary, in a funded pension system setup, the households' contributions go through the financial market that supports the productive sector. The pension system is somehow neutral with respect to savings, and the capital accumulation is preserved.
} 
Therefore, we have:

$$
z_{t}=\frac{\tau_{2}}{\phi_{t-1}} \omega_{t} \quad \text { because } L_{t}=L_{t-1}
$$

The pensions are equally distributed among surviving old households with a balanced budget. This explains that the individual pension $z_{t}$ depends on the longevity.

Subsequently, the equation (3) becomes:

$$
s_{t}=\frac{1}{1+\phi_{t}}\left(\phi_{t}\left(1-\tau_{1}-\tau_{2}\right) \omega_{t}-\frac{\tau_{2}}{r_{t+1}} \omega_{t+1}\right)
$$

This equation shows that even if the pension system lower savings, longevity remains associated with greater amount of income saved like Chakraborty (2004) and Raffin and Seegmuller (2014). In addition, the lifetime income is written $\Omega_{t}=\left(1-\tau_{1}-\tau_{2}\right) \omega_{t}+\tau_{2} \frac{\omega_{t+1}}{r_{t+1}}$ and life expectancy tends to reduce first period consumption (see equation 1).

\subsection{Environment degradation}

As previously mentioned, longevity is influenced by the stock of pollution as in Raffin and Seegmuller (2014). By a biodegradation process, there is a share $m$ of the stock of pollution that disappears from one period to the next. The environment degradation is nonetheless fueled by the production activity ${ }^{8}$ whereas cleaning activities supported by the government reduce it. In this paper, the dynamics of the stock of pollution is defined as follows (John and Pecchenino (1994), Jouvet et al. (2005), and Raffin and Seegmuller (2016)):

$$
\left.P_{t+1}=(1-m) P_{t}+a_{1} Y_{t}-a_{2} G_{t} \quad \text { with } m \in\right] 0,1\left[, a_{1} \geq 0, a_{2} \geq 0 \text { et } P_{0}>0\right. \text { known }
$$

The parameter $a_{1}$ accounts for the pollution rate of the productive sector and $a_{2}$ for the effectiveness of pollution abatement activities. However, these two opposite effects are linked because the more we produce, on the one hand the more polluted the environment is, and on the other hand, the more public authorities provide cleaning activities by levying more taxes on labor. Yet, in order to comply to what is observed, that is the net flow of pollution is strictly positive ${ }^{9}$, let us postulate the following assumption.

Assumption 1. $a_{1}>a_{2}$

\section{Equilibrium}

At the equilibrium in the labor market, the workforce $L_{t}$ involved in the production is equal to 1 . Besides that, all competitive firms used the same level of capital at the equilibrium and

\footnotetext{
${ }^{8}$ See Van Oort et al.(2007) and Huwart et al.(2012)

${ }^{9}$ See for instance National Oceanic and Atmospheric Administration, 2016. Record annual increase of carbon dioxide observed at Mauna Loa for 2015, US Department of Commerce
} 
this means $\bar{K}_{t}=K_{t}$. Therefore, equations (4) and (5) become

$$
\begin{aligned}
\omega_{t} & =(1-\alpha) A K_{t} \\
r_{t} & =\alpha A
\end{aligned}
$$

Production is given by $Y_{t}=A K_{t}$. Using equations (9) and (10), the savings can be rewritten $s_{t}=\frac{\phi_{t}}{1+\frac{1-\alpha}{\alpha} \tau_{2}+\phi_{t}}\left(1-\tau_{1}-\tau_{2}\right) \omega_{t}$. As Chakraborty (2004) and Varvarigos (2010), we can see that the saving rate depends on the endogenous longevity. Note that the term $\frac{1-\alpha}{\alpha} \tau_{2}$ in the denominator reflects the presence of a pension system. The more significant $\tau_{2}$ is, the lower the saving rate. Similarly, a greater labor share in income leads to the same result, because households anticipate a higher level of pension when old and therefore save less when young.

The equilibrium in the asset market is reached when savings financed the firms capital need, that is $K_{t+1}=s_{t}$, which is equivalent to

$$
K_{t+1}=\frac{\phi_{t}}{1+\frac{1-\alpha}{\alpha} \tau_{2}+\phi_{t}}(1-\alpha)\left(1-\tau_{1}-\tau_{2}\right) A K_{t}
$$

where longevity is

$$
\phi_{t}=b \frac{\mu \tau_{1}(1-\alpha) A \frac{K_{t}}{P_{t}}}{1+\mu \tau_{1}(1-\alpha) A \frac{K_{t}}{P_{t}}}
$$

The evolution of the stock of pollution becomes:

$$
P_{t+1}=(1-m) P_{t}+\left(a_{1}-a_{2}(1-\mu) \tau_{1}(1-\alpha)\right) A K_{t}
$$

Equations (11) - (13) give the dynamics of the economy, characterised by the evolution of capital and pollution. They highlight at least one complex mechanism: a longevity increase is associated with a saving rate rise, which stimulates more capital accumulation, but nevertheless this goes along with more environment degradation. Depending on which stock (capital or pollution) has increased more, the next generation life expectancy is affected. Also, let us note that longevity will be much more influenced as it is low, due to the concavity of $\phi_{t}$. Furthermore, the same rise in longevity has less and less impact on the saving rate when the pension system (the term $\frac{1-\alpha}{\alpha} \tau_{2}$ ) is more and more significant in the economy. In addition, due to endogenous growth, the stock of capital $\left(K_{t}\right)$ and pollution $\left(P_{t}\right)$ do not reach a stationary value in the long run. To better look at those two conflicting effects on longevity, and therefore on the dynamics, let define $x_{t} \equiv \frac{K_{t}}{P_{t}}$ the ratio of capital over pollution. The 
pollution growth factor, $g_{P_{t}}$, and capital growth factor, $g_{K_{t}}$, can be written:

$$
\begin{gathered}
g_{K_{t}} \equiv \frac{K_{t+1}}{K_{t}}=\frac{\phi_{t}}{1+\frac{1-\alpha}{\alpha} \tau_{2}+\phi_{t}}(1-\alpha)\left(1-\tau_{1}-\tau_{2}\right) A \\
g_{P_{t}} \equiv \frac{P_{t+1}}{P_{t}}=1-m+\left(a_{1}-a_{2}(1-\mu) \tau_{1}(1-\alpha)\right) A x_{t}
\end{gathered}
$$

Then, the economy dynamics can be described by the following equation

$$
x_{t+1}=\frac{\phi_{t}}{1+\frac{1-\alpha}{\alpha} \tau_{2}+\phi_{t}} \times \frac{(1-\alpha)\left(1-\tau_{1}-\tau_{2}\right) A x_{t}}{(1-m)+\left(a_{1}-a_{2}(1-\mu) \tau_{1}(1-\alpha)\right) A x_{t}}
$$

Substituting $\phi_{t}=\frac{b \mu \tau_{1}(1-\alpha) A x_{t}}{1+\mu \tau_{1}(1-\alpha) A x_{t}}$ into equation (16), we get:

$$
\begin{aligned}
x_{t+1}= & \frac{b \mu \tau_{1}(1-\alpha) A x_{t}}{1+(b+1) \mu \tau_{1}(1-\alpha) A x_{t}+\tau_{2} \frac{1-\alpha}{\alpha}\left(1+\mu \tau_{1}(1-\alpha) A x_{t}\right)} \\
& \times \frac{(1-\alpha)\left(1-\tau_{1}-\tau_{2}\right) A x_{t}}{(1-m)+\left(a_{1}-a_{2}(1-\mu) \tau_{1}(1-\alpha)\right) A x_{t}} \equiv \psi\left(x_{t}\right)
\end{aligned}
$$

The previous equation describes the long run evolution of the economy, with $x_{0}=\frac{K_{0}}{P_{0}} \geq 0$, both $K_{0} \geq 0$ and $P_{0}>0$ are given. To exhibit the balanced growth paths and their stability properties, we study the dynamics of $x_{t}$ and the existence of steady states.

\section{Balanced growth paths}

In this section, we aim to find out the conditions that allow for the existence of non-trivial steady states. Then, we study how economic policies might affect those conditions and finally, we tackle the stability properties of long run equilibria.

\subsection{Existence of steady states}

A steady state $x$, which corresponds to a balanced growth path (BGP), is such that $x_{t+1}=$ $x_{t} \equiv x$. From the equation (17), it is obvious that $x=0$ is a steady state. Non-trivial balanced growth paths $x$ satisfy the following equation.

$$
\begin{array}{r}
{\left[\left(1+\frac{1-\alpha}{\alpha} \tau_{2}\right)+\left(1+b+\frac{1-\alpha}{\alpha} \tau_{2}\right) \mu \tau_{1}(1-\alpha) A x\right]\left[(1-m)+\left(a_{1}-a_{2}(1-\mu) \tau_{1}(1-\alpha)\right) A x\right]=} \\
=b \mu \tau_{1}\left(1-\tau_{1}-\tau_{2}\right)(1-\alpha)^{2} A^{2} x
\end{array}
$$

The following proposition discusses the existence of multiple steady states. 
Proposition 1. Under Assumption 1, there exists a value $A_{1, \tau_{2}}>0$ such that:

1. For $A<A_{1, \tau_{2}}$, there exists a unique steady state which is $x=0$;

2. For $A>A_{1, \tau_{2}}$, in addition to $x=0$, there exist two non-zero steady states $x_{1}(>0)$ and $x_{2}\left(>x_{1}\right)$.

Proof. See Appendix 1.

This proposition states that the the multiplicity of steady states occurs only if the factors overall productivity $(A)$ is high enough. Indeed, if the productive sector has a low efficiency, on the one hand, labor tax revenues are not high enough to provide both sufficient health care services and cleaning activities to reduce the adverse effects of pollution on longevity, and therefore on the saving rate. On the other hand, wages are not high enough to compensate the adverse effect of pollution on the dynamics. In other words, the negative externality of the production activity, namely pollution, outweighs its benefits. These mechanisms are related to the endogenous longevity and the induced endogenous saving rate.

By the way, let us note that if we regard pollution as a flow, that is $m=1$, the multiplicity of non-zero steady states disappears as the ratio of labor income over pollution becomes constant over time. It shows the crucial role played by the pollution as a stock in the model.

For non zero steady states $x>0$, the stock of pollution and the level of capital have the same growth rate. In fact, $\forall t, x_{t+1}=x_{t} \Rightarrow \frac{K_{t+1}}{P_{t+1}}=\frac{K_{t}}{P_{t}}$, whence $\frac{K_{t+1}}{K_{t}}=\frac{P_{t+1}}{P_{t}}$. Therefore, the common growth factor associated is:

$$
\begin{aligned}
g_{K} & =\frac{b \mu \tau_{1}(1-\alpha) A x}{1+(b+1) \mu \tau_{1}(1-\alpha) A x+\tau_{2} \frac{1-\alpha}{\alpha}\left(1+\mu \tau_{1}(1-\alpha) A x\right)}(1-\alpha)\left(1-\tau_{1}-\tau_{2}\right) A \\
g_{P} & =(1-m)+\left(a_{1}-a_{2}(1-\mu) \tau_{1}(1-\alpha)\right) A x=g_{K}
\end{aligned}
$$

This shows us that at the highest steady state $\left(x_{2}\right)$, capital accumulation is faster that in the lower one $\left(x_{1}\right)$. Nevertheless, this also goes along with a greater pollution growth rate.

\subsection{The role of economic policies in the existence of steady states}

We are mainly interested in the effects of environmental and pensions policies on the long run equilibrium. For that purpose, let us see how policy parameters $\tau_{2}$ and $\mu$ affect the threshold value $A_{1, \tau_{2}}$. The result is summarized in the next proposition.

Proposition 2. Under Assumption 1, we have:

(i) Effect of the pension system: $\frac{\partial A_{1, \tau_{2}}}{\partial \tau_{2}}>0$ and $\lim _{\tau_{2} \rightarrow 0} A_{1, \tau_{2}}<\lim _{\tau_{2} \rightarrow 1-\tau_{1}} A_{1, \tau_{2}}=+\infty$;

(ii) Effect of the health policy: $\frac{\partial A_{1, \tau_{2}}}{\partial \mu}<0, \lim _{\mu \rightarrow 0} A_{1, \tau_{2}}=+\infty$ and $\lim _{\mu \rightarrow 1} A_{1, \tau_{2}}<+\infty$. 
Proof. See Appendix 2.

A more significant pension system, meaning a rise in $\tau_{2}$, reduces the likelihood of having multiple steady-states, by pushing up the global productivity threshold. This goes through a two-fold effect, the drop in the saving rate and the curtailment of the available income. Regarding the environmental policy, its impact on the existence of multiple equilibria is similar. The main channel in that case is the longevity effect. Indeed, all else equal, a higher share of environmental expenditures hampers longevity, through a reduction of the share of health budget, and hence is detrimental to the saving rate. On the contrary, a policy that favors health services helps to make non zero steady states attainable.

\subsection{Stability of steady states and traps}

We analyse the stability of balanced growths paths studying the recursive equation (17). A first step is to study the shape of $\psi(x)$. That is the aim of the following lemma.

Lemma 1. Under Assumption 1, $\psi(x)$ has the following properties:

- $\psi(0)=0=\psi^{\prime}(0), 0<\psi(\infty)<\infty, \psi^{\prime}(\infty)=0, \psi^{\prime}(x)>0$;

- $\psi(x)$ is a convex concave function.

Proof. See Appendix 3.

By inspection of equation (17), we identify the two main effects that play a role on $\psi(x)$, the first goes through the saving rate and the other through the net income over pollution. For low values of capital over pollution, the saving rate increases quickly because the longevity is highly sensitive to any modification of health over pollution. For higher levels of capital over pollution, the increase of longevity as well as of the net income over pollution becomes less significant.

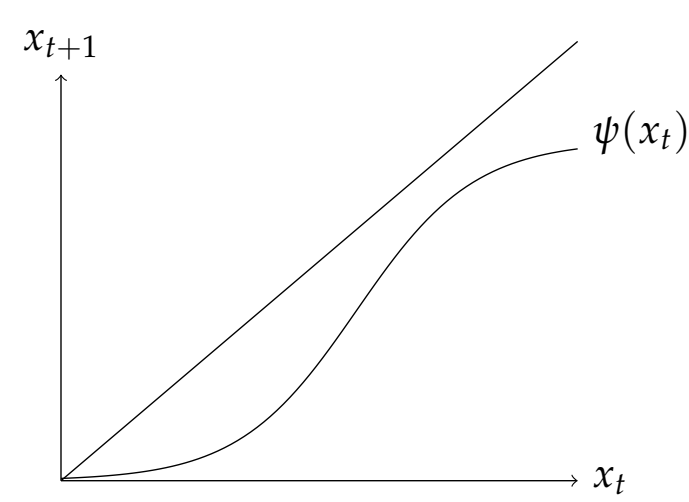

(a) When $A<A_{1, \tau_{2}}$

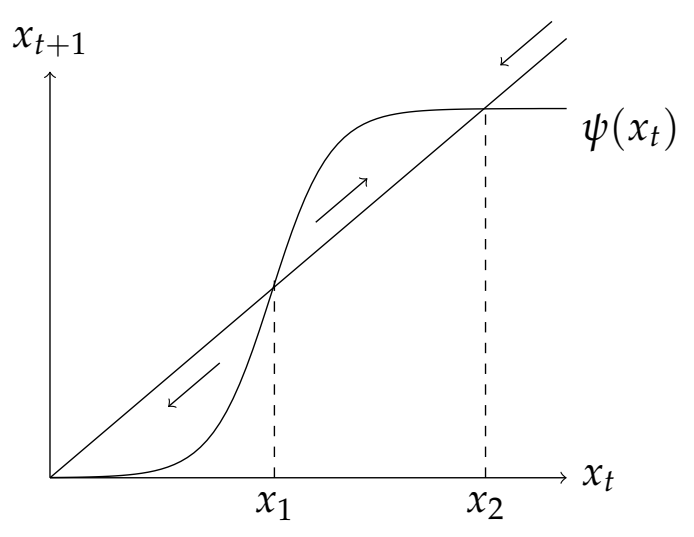

(b) When $A>A_{1, \tau_{2}}$

Figure 1: The dynamics of the economy 
This complex form of $\psi$ allows us to deduce that depending on its initial conditions $\frac{K_{0}}{P_{0}}$, the economy will not converge to the same BGP in the long run. This is the content of the next proposition about the existence of an environmental poverty trap and of a non zero stable steady state.

\section{Proposition 3. Under Assumption 1,}

1. For $A<A_{1, \tau_{2}}$, the only steady state $x=0$ is a stable equilibrium;

2. For $A>A_{1, \tau_{2}}$, the steady state $x_{1}$ is unstable, $x_{2}$ and $x=0$ are stable.

Proof. First, $\psi^{\prime}(0)=0<1$, that means the steady state $x=0$ is stable. Considering Lemma 1 , in the case there are non zero steady states, we necessarily have $\psi\left(x_{t}\right)<x_{t}$ for all $x_{t}<x_{1}$, $\psi\left(x_{t}\right)>x_{t}$ for all $x_{1}<x_{t}<x_{2}$ and $\psi\left(x_{t}\right)<x_{t}$ for all $x_{t}>x_{2}$. With $x_{t+1}=\psi\left(x_{t}\right)$, it is obvious that $x_{1}$ is an unstable steady state, while $x_{2}$ is a stable one. In the case $x=0$ is the only steady state, we always have $x_{t+1}=\psi\left(x_{t}\right)<x_{t}$ for all $x_{t}>0$.

At the steady state $x=0$, the stock of capital is constant and equal to 0 . However, since $P_{0}>0$, the level of pollution decrease steadily at the rate $m$, but never comes to 0 . The zero steady state is reached if and only if $K_{0}=0$. Otherwise, the stock of capital may go down but still remain positive.

In this paper, the global productivity and the initial level of the ratio of capital over pollution are key factors in the process of convergence. If the first one is too small, the labor income, and consequently health and environmental budgets are too weak, so that they fail to overcome the harmful effects of pollution on longevity, whatever the initial conditions that prevail in the economy. Then, $x_{t}$ decreases and converges towards 0 .

For $A$ sufficiently large, the initial ratio of capital over pollution has to be greater than $x_{1}$ in order to guarantee that the economy converges toward the non zero stable steady state. Indeed, when $A$ is high enough, if the initial stock of capital is not sufficiently large with regard to the initial stock of pollution, then the health care and cleaning activities budgets are reinforcing the adverse effect of the already significant stock of pollution on longevity. The low life expectancy leads youngs to opt for current consumption instead of savings. In such a configuration, capital decreases (or increases) faster (slower) than pollution and $x_{t}$ converges to the stable steady state $x=0$. During this decreasing phase, pollution growth factor is higher than capital one and remains greater than $1-m$ while capital growth factor becomes more and more closer to 0 .

On the other hand, if the initial stock of capital is sufficient high compared to the level of pollution, for example $x_{1}<x_{0}<x_{2}$, then health care and pollution abatements activities are sufficiently funded to be effective in lowering the effects of pollution on the length-of-life. 
The longer longevity fosters savings and capital goes up (down) faster (slower) than pollution stock, in such a way $x_{t}$ increases to the highest steady state $x_{2}$. During this convergence phase, the capital growth factor is higher than the pollution one, which goes up as well. At $x_{2}$, both are equal.

\subsection{The planner issue and the maximization of the growth rate}

The problem faced by a benevolent planner is to allocate the resource of the economy between the consumption of the young and the consumption of the seniors for each generation, past and future. The aim of this section is to make a link between this planner concern and the focus we are making on maximizing the growth rate by showing that the two approaches are equivalent.

First, we define the planner objective function $\mathcal{U}$ as a discounted sum of the life-time utility of all current and future generations, $\mathcal{U} \equiv \sum_{t=-1}^{\infty} \beta^{t} U\left(c_{t}, d_{t+1}\right)$, where $\beta$ is a discount factor. He maximizes this function under the constraints given by Equations (1), (2), (6), (9), (10) and (12). For the sake of simplicity, let us consider that the economy is at a BGP. Because the stock of pollution and of capital evolve at the same rate, the longevity is constant over time, that is, $\phi_{t}=\phi$. Therefore, the set of constraint implies that $c_{t}$ and $d_{t+1}$ are proportional to income $\omega_{t}$. We have $\mathcal{U}=\frac{\ln c_{-1}}{\beta}+\ln c_{0}+\frac{\phi}{\beta} \ln d_{0}+\sum_{t=1}^{\infty} \beta^{t}\left(\ln c_{t}+\phi \ln d_{t}\right)$. Hence, the planner issue is now to maximize $\overline{\mathcal{U}} \equiv \sum_{t=1}^{\infty} \beta^{t}\left(\ln c_{t}+\phi \ln d_{t}\right)=\sum_{t=0}^{\infty} \beta^{t+1}\left(\ln \left(b_{1} g_{t} K_{t}\right)+\frac{\phi}{\beta} \ln \left(b_{2} K_{t}\right)\right)$, where $c_{t}=b_{1} K_{t}, d_{t+1}=b_{2} K_{t}$ and $b 1, b 2>0$. Since $K_{0}$ is given and $g_{t}=g$ at a BGP, we have that $K_{t}=g^{t} K_{0}$. Then, we can write $\overline{\mathcal{U}}=\sum_{t=0}^{\infty} \beta^{t+1}\left(\ln \left(\lambda_{0} g^{t+1} K_{0}\right)+\frac{\phi}{\beta} \ln \left(\lambda_{1} g^{t} K_{0}\right)\right)$. Given that $K_{0}$ is given, this expression is maximized when the growth rate of capital, $g$, is maximized.

This explains why we focus in the following sections on the effects of economic policies on the growth rate of the capital.

\section{Effects of economic policies}

Let us now analyse how economic policies affect the long run dynamics of the ratio of capital over pollution. First, we study the effects of pension system and secondly, we focus on the environmental policy. Finally, in the last part of this section, we are interested in how the pension system could affect the efficiency of health and environmental policies. 


\subsection{The effects of the pension system on the long run equilibria}

The public pension system acts as a disincentive to saving. It both affects the saving rate and the available income.

Proposition 4. Under Assumption 1, we always have $\frac{\partial \psi(x)}{\partial \tau_{2}}<0$. In addition, for $A>$ $A_{1, \tau_{2}}$, the following holds: $\frac{\mathrm{d} x_{1}}{\mathrm{~d} \tau_{2}}>0$ and $\frac{\mathrm{d} x_{2}}{\mathrm{~d} \tau_{2}}<0$.

Proof. See Appendix 4.

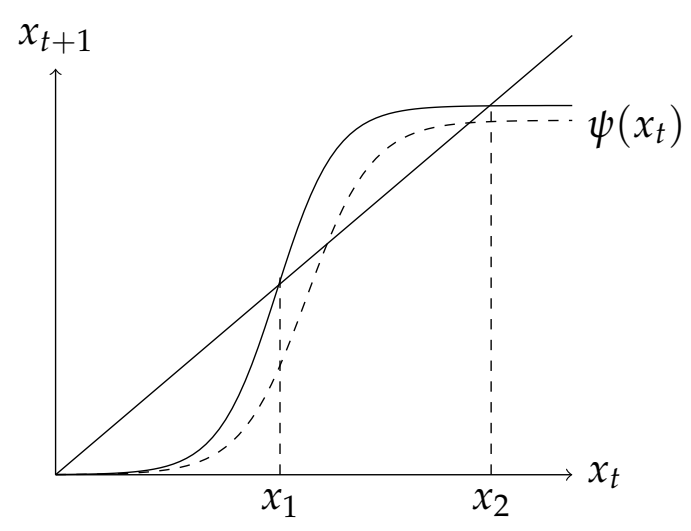

Figure 2: An increase in $\tau_{2}$

When the level of productivity in the economy is high enough, a more important pension system (that is $\tau_{2}$ goes up) enlarges the environmental poverty trap and lowers the ratio of capital over pollution at the stable steady state. An economy with $x_{t}$ slightly higher than $x_{1}$, may be driven into the environmental poverty trap following a rise in the pension system size. An increase in the tax that funds pension not only diminishes the saving rate, but also reduces the available income of households. Consequently, the stock of capital decreases with respect to the stock of pollution; not only at the BGP, but whatever the stage of development of that economy. This is the disincentive effect of pension system, which is well documented in the literature (Attanasio and Rohwedder, 2003).

\subsection{The effects of the environmental policy on the long run equilibria}

In the model, a policy that promotes environmental safeguards displays two conflicting effects on the capital-pollution ratio, a negative longevity-related effect and a positive effect through pollution abatement. Indeed, an decrease in $\mu$ for a given $\tau_{1}$, means less health facilities, less hospital beds, etc., that dampen longevity, particularly when the level of development of the country (the ratio $K_{t} / P_{t}$ ) is low. Besides that, a lower $\mu$ implies a strengthening of the importance of pollution abatement activities, that is, more garbage collected, more green spaces, etc. and therefore less pollution. Between the two, identifying the prevailing effect depends on the sign of $\frac{\partial \psi(x)}{\partial \mu}$. This is the aim of the following lemma.

Lemma 2. Under Assumption 1, there exists a unique value $x^{\star}>0$ such that: 
- For all $0<x \leq x^{\star}, \frac{\partial \psi(x)}{\partial \mu} \geq 0$;

- For all $x>x^{\star}, \frac{\partial \psi(x)}{\partial \mu}<0$.

Proof. See the Appendix 5.

From the equation describing the dynamics of the economy, a rise in the share of tax revenues devoted to environmental activities leads to a decrease in the life expectancy and therefore in the saving rate, and in the same time, to a fall in the pollution stock. One can also note that the (negative) consequences on health spending of such a move are contemporaneous and immediate, whereas its (positive) effects on the stock of pollution are delayed to the next period. Besides, the concavity of the longevity function also plays a role to determine the dominating effect between the two above-mentioned. If the capital-pollution ratio is low, the negative effect through longevity overwhelms the second because concavity makes longevity more sensitive to variations occurring at lower values of capital over pollution. For the same reason, longevity decline is weak when the capital-pollution ratio is high and therefore, the pollution effect dominates. This also implies there is a threshold beyond which the pollution effect prevails over the longevity one. Hence, depending on the position of this threshold with respect to the steady states, we could clearly establish abatement activities effects in the long run, in the following proposition.

Proposition 5. Under Assumption 1 and $A>A_{1, \tau_{2}}$

1. If $x_{1}>x^{\star}$, an increase in $\mu$ enlarges the environmental poverty trap and reduces the ratio of capital over pollution at the stable steady state;

2. If $x_{1}<x^{\star}<x_{2}$, an increase in $\mu$ reduces the size of the poverty trap, as well as the ratio of capital over pollution at the highest steady state;

3. If $x_{2}<x^{\star}$, a rise in $\mu$ reduces the size of the environmental poverty trap and increases the ratio of capital over pollution at the stable steady state.

We can notice that in the case 1 , that corresponds to the figure $3 a$, reducing the share of resources devoted to pollution abatement activities has the same effects on the equilibria than a rise in the pension system size mentioned in Proposition 4. An economy initially located close on the right-hand side of $x_{1}$ could fall into the environmental poverty trap following a decrease in $\mu$. On the contrary, in the case 3 , a less ambitious environmental policy may allow one economy stuck in the trap to escape it and to converge towards the highest steady state (Figure 3c). The detrimental effects on longevity are outweighed by the positive ones on pollution. The same mechanism occurs in part in the case 2 (Figure 3b). Nevertheless, the impact of a timid environmental policy is more mitigated. On the one hand, one economy that would have got stuck in the environmental poverty trap might converge towards the highest steady state. On the other hand, disengagement from environmental issues lowers 
the value of capital - pollution ratio at the highest stationary equilibrium.

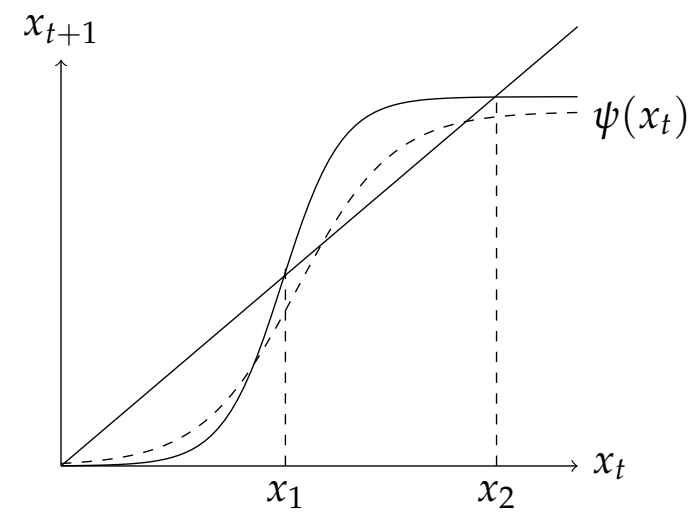

(a) When $x^{\star}<x_{1}$

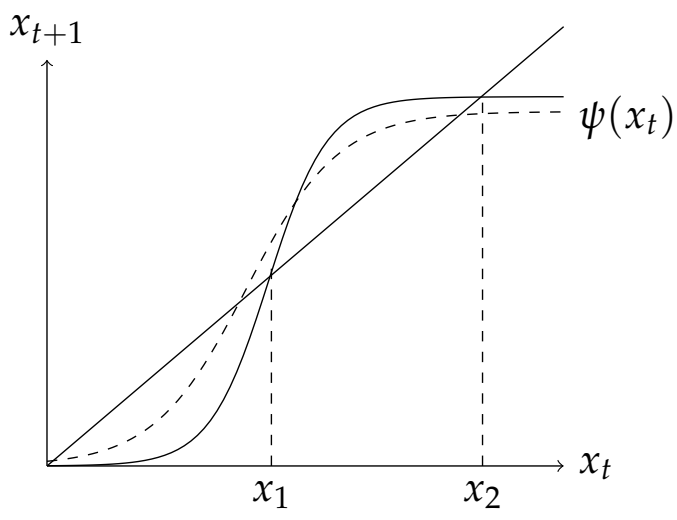

(b) When $x_{1}<x^{\star}<x_{2}$

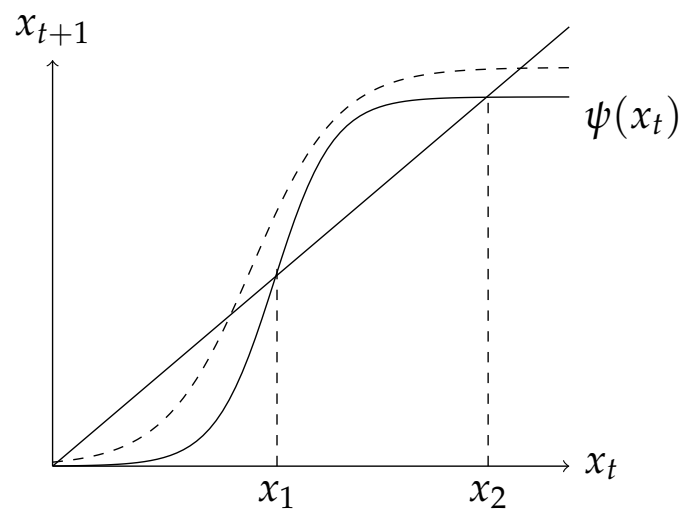

(c) When $x^{\star}>x_{2}$

Figure 3: An increase in $\mu$

To summarize, the effect of the environmental policy on stationary equilibria depends on the position of the threshold $x^{\star}$ relatively to $x_{1}$ and $x_{2}$. In this regard, the next subsection aims to try to find the prevailing case, between the three of the previous proposition, depending on the values of $\tau_{2}$. After looking at the baseline case where $\tau_{2}=0$, we examine the case of a non zero pension rate.

\subsection{The effects of the pension system on the efficiency of the environ- mental policy}

We discuss how the size of the pension system may affect the efficiency of the environmental policy. Does an increase of the share of budget devoted to health, and consequently a decrease in the share of resources for environmental issues, have greater benefits when the pension system is more important? To answer this question, let see first the effects of a policy that aims at preserving the environmental quality when there is no intergenerational solidarity, as in Raffin and Seegmuller (2014). 
Proposition 6. Under Assumption 1 and $\tau_{2}=0$, there exists $A_{0}^{\star}>A_{1, \tau_{2}}$ such that for $A>A_{0}^{\star}$, we have $x_{1}<x^{\star}<x_{2}$.

In the absence of a pension system, an increase in $\mu$ results in a shrinkage of the poverty trap and in the reduction of the ratio of capital over pollution at the highest steady state.

Proof. See Appendix 6.

When there is no pension system, and the global productivity is large enough, the stable steady state is higher, whereas the environmental poverty trap is downsized, following an increase in $\mu$. Therefore in this case, due to the concavity of longevity, pollution has the dominating effect around $x_{2}$. On the other hand, longevity is much more sensitive for lower values and that explain why around $x_{1}$, the saving rate effect holds sway instead. Note that this remains true whatever the size of the pension system.

We previously underscore that the effects of the environmental policy depend on the threshold value $x^{\star}$, and on $x_{1}$ and $x_{1}$, the non trivial steady states. The next lemma tells us which case of Proposition 5 occurs, according to the size of the pension system.

Lemma 3. Under Assumption 1, and for $A>A_{0}^{\star}$,

- $x^{\star}$ is increasing in $\tau_{2}$;

- There exist $\overline{\tau_{2}}$ and $\underline{\tau_{2}}$ such that $x_{1}<x^{\star}<x_{2}$ for all $\tau_{2}<\underline{\tau_{2}}$ and $x^{\star}>x_{2}$ for all $\tau_{2}>\overline{\tau_{2}}$.

Proof. See Appendix 7.

The threshold of capital-pollution ratio for which longevity effects, following a rise in $\mu$ is exactly offset by noxious feedbacks of pollution, goes up with the size of the pension system. This means that for a higher pension paid to retired households, the saving rate effect is strengthened with respect to the pollution one. This happens in two steps. First, as stated in Proposition 4, a higher $\tau_{2}$ is associated with a decline of the capital-pollution ratio $x_{t}$ due to a drop in saving rate and net income. Second, when $\mu$ raises, because capital-pollution ratio is lowered, concavity of longevity makes the marginal effect on the saving rate of the rise in $\mu$ bigger. We deduce that for economies in which the pension system is more significant, the capital-pollution ratio is lower and the environmental policy dampens much more the saving rate than it reduces the level of pollution. This gives us a first insight of how the pay-as-you-go pension system could affect the efficiency of such a policy.

The second point of the lemma displays two different cases related to pension system. A case of a low importance of intergenerational solidarity, in which we get the same effects of the environmental policy as without pension system, and the other case with important intergenerational transfers, that introduces new environmental policy effects on the long run dynamics of an economy. The latter are summarized in the following proposition. 
Proposition 7. Under Assumption 1 and for A large enough, when the pension system is significant enough $\left(\tau_{2}>\overline{\tau_{2}}\right)$, the environmental policy:

\section{Enlarges the poverty trap;}

2. Undermines economic growth, longevity and the capital-pollution ratio featuring the highest BGP.

When the size of the pension system $\tau_{2}$ is lower than $\underline{\tau_{2}}$, we are in the case 2 of Proposition 5. The pollution-related effect of the environmental policy is strong enough to dominate its adverse effect on longevity, for countries located around the stable steady state. In that case, economies converge towards a lower capital-pollution ratio following an increase in $\mu$.

For a contribution rate $\tau_{2}$ higher than $\overline{\tau_{2}}$, we are in the case 3 of Proposition 5 and the threshold value $x^{\star}$ is greater that $x_{2}$. Countries converging to $x_{2}$ converge towards a higher capital-pollution ratio following a rise in $\mu$ because the longevity related effect overwhelms the pollution effect. In addition to that, the growth rate at the stable BGP increases as a consequence, so does life expectancy.

We show that we come up with opposite findings than Raffin and Seegmuller (2014) when the pension system is high enough $\left(\tau_{2}>\overline{\tau_{2}}\right)$, regarding the effects of the environmental policy on the long run dynamics of rich countries.

Differences in health or environmental policies efficiency across developed countries may be explained by the wide range of sizes of pension system across those economies. Therefore, intergenerational solidarity appears as a policy instrument for a rich country to increase individuals' life expectancy, to boost economic growth and finally to make its health/environmental policy more efficient. That is due to the fact the longevity effect related to health policy is reinforced, relatively to the pollution effect, by a more important pension system.

The story is not the same for a poor country. Whatever the size of the pension system, fostering the health policy instead of pollution abatement measures could allow the country to escape the poverty trap.

In terms of policy recommendations, we suggest that:

- Economies experiencing low growth rates should devote a higher share of their budget to health issues relatively to the share allocated to the environment preservation, because their redistributive pension system is already high enough;

- On the contrary, fostering the health policy is not efficient for fast-growing economies because their public pension system size is still lower than the critical threshold. Instead, they should invest more in pollution abatement activities. 


\section{Conclusion}

We have investigated the effect of a PAYG pension system on the efficiency of health/environmental policy. For that purpose, we have built an OLG model where households are alive only for a fraction of the second period of their life, the retirement period. Longevity increases with public health expenditures but suffers from pollution. In addition to health expenditures and pollution abatement activities, the public authorities finance a balanced PAYG pension system. The global dynamics displays two non trivial steady-states, whose the higher is stable. A policy that promotes the environmental budget at the expense of health care measures, enlarges the size of the environmental poverty trap. However, in the same time, it raises the level of capital over pollution at the stable long run equilibrium, to which converge rich countries. This is due to the concavity of the longevity function, that makes the same longevity loss, that goes along with a smaller share of health expenditures, less costly for a more developed country. Nevertheless, we show that when the size of the pension system is big enough, this positive effect of the environmental policy does not hold anymore in rich countries. Consequently, less developed ones should firstly stress on extending the health system relatively to the pollution abatement activities, while rich one should extend the intergenerational solidarity before investing more on health relatively to environmental issues. 


\section{Appendix}

\section{Appendix 1. Proof of Proposition 1}

The equation (18) is equivalent to

$$
\begin{aligned}
& \qquad \theta(x) \equiv D_{0} x^{2}+D_{1} x+D_{2}=0 \\
& \text { where } D_{0}=\left(1+b+\frac{1-\alpha}{\alpha} \tau_{2}\right) \mu \tau_{1}(1-\alpha)\left(a_{1}-a_{2}(1-\mu) \tau_{1}(1-\alpha)\right) A^{2} \\
& \qquad D_{1}=\left[\left(1+\frac{1-\alpha}{\alpha} \tau_{2}\right)\left(a_{1}-a_{2}(1-\mu) \tau_{1}(1-\alpha)\right) A+\left(1+b+\frac{1-\alpha}{\alpha} \tau_{2}\right) \mu \tau_{1}(1-m)(1-\alpha) A-b \mu \tau_{1}\left(1-\tau_{1}-\tau_{2}\right)(1-\alpha)^{2} A^{2}\right] \\
& D_{2}=\left(1+\frac{1-\alpha}{\alpha} \tau_{2}\right)(1-m)>0
\end{aligned}
$$

Under Assumption $1, \theta^{\prime \prime}(0)>0$ and $\theta(0)>0$. That means $\theta$ has either 0 or 2 strictly positive roots. The equation (20) has 2 positive solutions if and only if $D_{1}^{2}>4 D_{0} D_{2}$ and $D_{1}<0$, that is

$$
\begin{gathered}
b \mu \tau_{1}\left(1-\tau_{1}-\tau_{2}\right)(1-\alpha)^{2} A-\left(1+\frac{1-\alpha}{\alpha} \tau_{2}\right)\left(a_{1}-a_{2}(1-\mu) \tau_{1}(1-\alpha)\right) \\
-\left(1+b+\frac{1-\alpha}{\alpha} \tau_{2}\right) \mu \tau_{1}(1-m)(1-\alpha) \\
>2 \sqrt{\left(1+\frac{1-\alpha}{\alpha} \tau_{2}\right)(1-m)\left(1+b+\frac{1-\alpha}{\alpha} \tau_{2}\right) \mu \tau_{1}(1-\alpha)\left(a_{1}-a_{2}(1-\mu) \tau_{1}(1-\alpha)\right)}
\end{gathered}
$$

Let us set $A_{1, \tau_{2}}=\frac{\Gamma_{1}}{\Gamma_{0}}$ with $\Gamma_{1}$ are $\Gamma_{0}$ are such that:

$$
\begin{gathered}
\Gamma_{1}=2 \sqrt{\left(\alpha+\tau_{2}(1-\alpha)\right)(1-m)\left(\alpha(b+1)+\tau_{2}(1-\alpha)\right) \mu \tau_{1}(1-\alpha)\left(a_{1}-a_{2}(1-\mu) \tau_{1}(1-\alpha)\right)} \\
+\left(\alpha(b+1)+\tau_{2}(1-\alpha)\right) \mu \tau_{1}(1-m)(1-\alpha)+\left(\alpha+\tau_{2}(1-\alpha)\right)\left(a_{1}-a_{2}(1-\mu) \tau_{1}(1-\alpha)\right) \\
\Gamma_{0}=b \alpha \mu \tau_{1}\left(1-\tau_{1}-\tau_{2}\right)(1-\alpha)^{2}
\end{gathered}
$$

Hence, we have 2 non-zero steady states when $A>A_{1, \tau_{2}}$ and only the trivial steady state otherwise. The proposition is proved.

\section{Appendix 2. Proof of Proposition 2}

To show $(i)$, we have:

$$
\begin{aligned}
\frac{\partial \Gamma_{1}}{\partial \tau_{2}}=\sqrt{(1-m) \mu \tau_{1}(1-\alpha)\left(a_{1}-a_{2}(1-\mu) \tau_{1}(1-\alpha)\right)} \frac{\alpha(1-\alpha)(b+2)+2(1-\alpha)^{2} \tau_{2}}{\sqrt{\left(\alpha+\tau_{2}(1-\alpha)\right)\left(\alpha(b+1)+\tau_{2}(1-\alpha)\right)}}+ \\
+\mu \tau_{1}(1-m)(1-\alpha)^{2}+(1-\alpha)\left(a_{1}-a_{2}(1-\mu) \tau_{1}(1-\alpha)\right)>0
\end{aligned}
$$


By the way, $\frac{\partial \Gamma_{0}}{\partial \tau_{2}}=-b \alpha \mu \tau_{1}(1-\alpha)^{2}<0$. Since $\Gamma_{0}$ and $\Gamma_{1}$ are both greater than 0 , we have then $\frac{\partial A_{1, \tau_{2}}}{\partial \tau_{2}}>0$

$\lim _{\tau_{2} \rightarrow 0} A_{1, \tau_{2}}<+\infty$ because $\lim _{\tau_{2} \rightarrow 0} \Gamma_{1}<+\infty$ and $\lim _{\tau_{2} \rightarrow 0} \Gamma_{0}<+\infty$. Besides that, $\lim _{\tau_{2} \rightarrow 1-\tau_{1}} \Gamma_{0}=0$ and $\lim _{\tau_{2} \rightarrow 1-\tau_{1}} \Gamma_{1}<+\infty$ lead to $\lim _{\tau_{2} \rightarrow 1-\tau_{1}} A_{1, \tau_{2}}=+\infty$.

For the second item $(i i)$, let $\mu_{G}=1-\mu$. Therefore, we have:

$$
\begin{aligned}
\Gamma_{0} \frac{\partial \Gamma_{1}}{\partial \mu_{G}} & -\Gamma_{1} \frac{\partial \Gamma_{0}}{\partial \mu_{G}}=b \alpha \tau_{1} \mu\left(1-\tau_{1}-\tau_{2}\right)(1-\alpha)^{2} \sqrt{(1-m) \tau_{1}(1-\alpha)\left(\alpha+\tau_{2}(1-\alpha)\right)\left(\alpha(b+1)+\tau_{2}(1-\alpha)\right)} \\
& \times \frac{a_{1}-a_{2} \tau_{1}(1-\alpha)}{\sqrt{\mu\left(a_{1}-a_{2} \mu_{G} \tau_{1}(1-\alpha)\right)}}+b \alpha \tau_{1}\left(1-\tau_{1}-\tau_{2}\right)(1-\alpha)^{2}\left[\left(\alpha+\tau_{2}(1-\alpha)\right)\left(a_{1}-a_{2} \tau_{1}(1-\alpha)\right)\right] \quad>0
\end{aligned}
$$

Hence, we have $\frac{\partial A_{1, \tau_{2}}}{\partial \mu}<0$. In addition, $\lim _{\mu \rightarrow 0} \Gamma_{1}<\infty$ and $\lim _{\mu \rightarrow 0} \Gamma_{0}=0 \Rightarrow \lim _{\mu \rightarrow 0} A_{1, \tau_{2}}=+\infty$. Similarly, we obtain $\lim _{\mu \rightarrow 1} A_{1, \tau_{2}}<+\infty$.

\section{Appendix 3. Proof of Lemma 1}

It is obvious that $\psi(0)=0$ and $\lim _{x \rightarrow 0} \frac{\psi(x)}{x}=0$. Therefore, $\psi^{\prime}(0)=0$.

Let $Q_{0}(x)=\frac{b \mu \tau_{1}(1-\alpha) A x}{\alpha\left(1+(b+1) \mu \tau_{1}(1-\alpha) A x\right)+\tau_{2}(1-\alpha)\left(1+\mu \tau_{1}(1-\alpha) A x\right)}$ and

$$
Q_{1}(x)=\frac{\alpha(1-\alpha)\left(1-\tau_{1}-\tau_{2}\right) A x}{1-m+\left(a_{1}-a_{2}(1-\mu) \tau_{1}(1-\alpha)\right) A x}
$$

We have $Q_{0}^{\prime}(x)>0$ and $Q_{1}^{\prime}(x)>0$, hence $\psi$ is increasing. In addition, let us denote $\Xi(x)$ the denominator of $\psi(x)$. Therefore, $\psi^{\prime}(x)=b \alpha \mu \tau_{1}\left(1-\tau_{1}-\tau_{2}\right)(1-\alpha)^{2} A^{2} \frac{2 x \Xi(x)-x^{2} \Xi^{\prime}(x)}{\Xi^{2}(x)}$ for $x>0$. The numerator of $\psi^{\prime}(x)$ is a third order polynomial in $x$ and its denominator a fourth order one. That is why $\lim _{x \rightarrow \infty} \psi^{\prime}(x)=0$, and hence, $\psi(+\infty)<+\infty$. Furthermore, $\psi^{\prime \prime}(x)$ has the same sign than $I(x)=\left(2 \Xi(x)-x^{2} \Xi^{\prime \prime}(x)\right) \Xi(x)-2\left(2 x \Xi(x)-x^{2} \Xi^{\prime}(x)\right) \Xi^{\prime}(x)$. $\Xi(x)$ is a polynomial of degree 2 , and let us set $\Xi(x)=\beta_{0} x^{2}+\beta_{1} x+\beta_{2}$. Therefore, we have $I(x)=-2\left(\beta_{0} \beta_{1} x^{3}+3 \beta_{0} \beta_{2} x^{2}-\beta_{2}^{2}\right)$ and $I^{\prime}(x)=-6 \beta_{0} x\left(\beta_{1} x+2 \beta_{2}\right)<0$ (because $\beta_{0}, \beta_{1}$, $\left.\beta_{2} \in \mathcal{R}^{+}\right)$. Yet, $I(0)=2 \beta_{2}^{2}>0$ and $I(\infty)=-\infty$. That implies there exists a unique $x^{\star}>0$ such as $\psi^{\prime \prime}(x)>0$ for all $x<x^{\star}$ and $\psi^{\prime \prime}(x)<0$ for all $x>x^{\star}$. Then, $\psi(x)$ is convex-concave.

\section{Appendix 4. Proof of Proposition 4}

Let us set $\psi(x)=C_{0}(x) \frac{1-\tau_{1}-\tau_{2}}{P_{0}(x)}$ with $C_{0}(x)=\frac{b \alpha \mu \tau_{1}(1-\alpha)^{2} A^{2} x^{2}}{1-m+\left(a_{1}-a_{2}(1-\mu) \tau_{1}(1-\alpha)\right) A x}$.

$P_{0}(x)=\underbrace{\alpha\left(1+(b+1) \mu \tau_{1}(1-\alpha) A x\right)}_{a(x)}+\underbrace{(1-\alpha)\left(1+\mu \tau_{1}(1-\alpha) A x\right)}_{b(x)} \tau_{2} \equiv a(x)+b(x) \tau_{2}$.

Therefore, $\frac{\partial \psi(x)}{\partial \tau_{2}}=C_{0}(x) \frac{-a-\left(1-\tau_{1}\right) b}{P_{0}^{2}(x)}<0$ for $x>0$ because $C_{0}(x)>0, a(x)>0$ and 
$b(x)>0$. Note that $\forall \tau_{2}, \psi(0)=0$.

A non trivial steady state $x \in\left\{x_{1}, x_{2}\right\}$ is a solution of the equation $F(x) \equiv \psi(x)-x=0$. Hence $\mathrm{d} F(x)=\frac{\partial F(x)}{\partial x} \mathrm{~d} x+\frac{\partial F(x)}{\partial \tau_{2}} \mathrm{~d} \tau_{2}=0$. That gives:

$$
\frac{\mathrm{d} x}{\mathrm{~d} \tau_{2}}=-\frac{\partial \psi(x) / \partial \tau_{2}}{\partial \psi(x) / \partial x-1}
$$

We can note that for $x=x_{1}$, the denominator of the Equation (22) is greater than 0 and negative for $x=x_{2}$. That is why $\frac{\mathrm{d} x_{1}}{\mathrm{~d} \tau_{2}}>0$ and $\frac{\mathrm{d} x_{2}}{\mathrm{~d} \tau_{2}}<0$.

\section{Appendix 5. Proof of Lemma 2}

Let $\psi(x)=b \tau_{1}\left(1-\tau_{1}-\tau_{2}\right)(1-\alpha)^{2} A^{2} x^{2} \frac{\mu}{B_{x}(\mu)}$ where $B_{x}(\mu) \equiv\left[\alpha\left(1+(b+1) \mu \tau_{1}(1-\alpha) A x\right)+(1-\alpha)\left(1+\mu \tau_{1}(1-\alpha) A x\right)\right]\left[1-m+\left(a_{1}-a_{2}(1-\mu) \tau_{1}(1-\alpha)\right) A x\right]$.

$B_{x}(\mu)$ is a second order polynomial. Hence, for $x>0, \frac{\partial \psi(x)}{\partial \mu}$ has the sign of $B_{x}(\mu)-$ $\mu B_{x}^{\prime}(\mu) \equiv P(x)$, which is a second order polynomial in $x: P(x) \equiv\left(\alpha+\tau_{2}(1-\alpha)\right)(1-$ $\left.m+\left(a_{1}-a_{2} \tau_{1}(1-\alpha)\right) A x\right)-a_{2}\left[\alpha(b+1)+\tau_{2}(1-\alpha)\right] \tau_{1}^{2}(1-\alpha)^{2} A^{2} \mu^{2} x^{2}$ Because $P^{\prime \prime}(0)<0$ and $P(0)>0$, the equation $P(x)=0$ has a unique solution $x^{\star}>0$. That is why $P(x) \geq 0$ for $0<x \leq x^{\star}$ and $P(x)<0$ for $x>x^{\star}$.

\section{Appendix 6. Proof of Proposition 6}

For a given value of $\tau_{2}$, we have $x^{\star}=\frac{E}{2 a_{2}\left(\alpha(b+1)+\tau_{2}(1-\alpha)\right) \tau_{1}^{2}(1-\alpha)^{2} \mu^{2} A}$ and

$$
\begin{aligned}
x_{i} & =\frac{-D_{1} \pm \sqrt{D_{1}^{2}-4 D_{0} D_{2}}}{2\left(1+b+\frac{1-\alpha}{\alpha} \tau_{2}\right) \mu \tau_{1}(1-\alpha)\left(a_{1}-a_{2}(1-\mu) \tau_{1}(1-\alpha)\right) A^{2}} \text { with }^{10} i \in\{1,2\} \text { and } \\
E & \equiv\left(\alpha+\tau_{2}(1-\alpha)\right)\left(a_{1}-a_{2} \tau_{1}(1-\alpha)\right)+ \\
& +\sqrt{\left(\alpha+\tau_{2}(1-\alpha)\right)^{2}\left(a_{1}-a_{2} \tau_{1}(1-\alpha)\right)^{2}+4 a_{2}(1-m)\left(\alpha+\tau_{2}(1-\alpha)\right)\left(\alpha(b+1)+\tau_{2}(1-\alpha)\right) \tau_{1}^{2}(1-\alpha)^{2} \mu^{2}}
\end{aligned}
$$

Therefore, $x^{\star}-x_{i}$ has the sign of $f(A) \equiv C+\left(\alpha_{0}-\beta_{0} A\right) \pm \sqrt{\left(\alpha_{0}-\beta_{0} A\right)^{2}-\lambda_{0}}$ with: $\lambda_{0} \equiv 4\left[a_{2} \mu \tau_{1}(1-\alpha)\right]^{2}\left(\alpha(b+1)+\tau_{2}(1-\alpha)\right) \mu \tau_{1}(1-\alpha)\left(a_{1}-a_{2}(1-\mu) \tau_{1}(1-\alpha)\right)\left(\alpha+\tau_{2}(1-\alpha)\right)(1-m)>0$, $C \equiv\left(a_{1}-a_{2}(1-\mu) \tau_{1}(1-\alpha)\right) E>0$ and $\alpha_{0}-\beta_{0} A \equiv a_{2} \alpha \mu \tau_{1}(1-\alpha) D_{1} / A$ where $\alpha_{0}, \beta_{0}, \lambda_{0} \in \mathcal{R}^{+}$. We have $f\left(A_{1, \tau_{2}}\right)=C-\sqrt{\lambda_{0}}$ because ${ }^{11} A_{1, \tau_{2}}=\frac{\alpha_{0}+\sqrt{\lambda_{0}}}{\beta_{0}} . x^{\star}-x_{2}$ has the sign of $f^{-}(A) \equiv C+\left(\alpha_{0}-\beta_{0} A\right)-\sqrt{\left(\alpha_{0}-\beta_{0} A\right)^{2}-\lambda_{0}}$. By the way, $f^{-}(+\infty)=-\infty<0$ and

\footnotetext{
${ }^{10} D_{0}, D_{1}$ and $D_{2}$ are defined in Appendix 1.

${ }^{11} A_{1, \tau_{2}}$, the global productivity threshold for the existence of multiple steady states, is defined to ensure that $\left(\alpha_{0}-\beta_{0} A\right)^{2}-\lambda_{0}>0$.
} 
$\left(f^{-}\right)^{\prime}(A)=-\beta_{0}\left[1-\frac{\alpha_{0}-\beta_{0} A}{\sqrt{\left(\alpha_{0}-\beta_{0} A\right)^{2}-\lambda_{0}}}\right]<0$ since $D_{1}<0$. Hence, if $f^{-}\left(A_{1, \tau_{2}}\right)<0$ then $f^{-}(A)<0$ for all $A>A_{1, \tau_{2}}$. Otherwise, there exists a unique $A^{\prime \star} \equiv A^{\prime \star}\left(\tau_{2}\right)>A_{1, \tau_{2}}$ such that $f^{-}(A)>0$ for all $A<A^{\prime \star}\left(\tau_{2}\right)$ and $f^{-}(A)<0$ for all $A>A^{\prime \star}\left(\tau_{2}\right)$.

Similarly, $x^{\star}-x_{1}$ has the sign of $f^{+}(A) \equiv C+\left(\alpha_{0}-\beta_{0} A\right)+\sqrt{\left(\alpha_{0}-\beta_{0} A\right)^{2}-\lambda_{0}}$. We have $f^{+}(+\infty)=C>0$ and $\left(f^{+}\right)^{\prime}(A)=-\beta_{0}\left[1+\frac{\alpha_{0}-\beta_{0} A}{\sqrt{\left(\alpha_{0}-\beta_{0} A\right)^{2}-\lambda_{0}}}\right]>0$ since $\left|\alpha_{0}-\beta_{0} A\right|>$ $\sqrt{\left(\alpha_{0}-\beta_{0} A\right)^{2}-\lambda_{0}}$. Hence, if $f^{+}\left(A_{1, \tau_{2}}\right)>0$ then $f^{+}(A)>0$ for all $A>A_{1, \tau_{2}}$. Otherwise, there exists a unique $A^{\prime \prime \star}\left(\tau_{2}\right)>A_{1, \tau_{2}}$ such that $f^{+}(A)<0$ for all $A<A^{\prime \prime \star}\left(\tau_{2}\right)$ and $f^{+}(A)>$ 0 for all $A>A^{\prime \prime \star}\left(\tau_{2}\right)$. By the way, let us notice that the solution $A^{\star}>0$ of $f(A)=0$, when it exists, is unique and has the same value whatever the sign of $f\left(A_{1, \tau_{2}}\right)$. Hence, we have $A^{\prime \star}=A^{\prime \prime \star} \equiv A^{\star}$.

To summarize, whatever the case, there always exists a threshold value $A^{\star}\left(\tau_{2}\right)>A_{1, \tau_{2}}$ such that for all $A>A^{\star}\left(\tau_{2}\right)$, we both have $f^{-}(A)<0$ and $f^{+}(A)>0$. When $\tau_{2}=0$, we have $A_{0}^{\star} \equiv A^{\star}(0)$. The proposition is proved.

\section{Appendix 7. Proof of Lemma 3}

Let us start with $(i)$.

$x^{\star}>0$ is such that $P\left(x^{\star}\right)=0 .{ }^{12}$ Let us define $H(x) \equiv \frac{1}{1-\alpha} \frac{\partial P(x)}{\partial \tau_{2}}$. We have $H(x)=1-m+\left(a_{1}-a_{2} \tau_{1}(1-\alpha)\right) A x-a_{2} \tau_{1}^{2}(1-\alpha)^{2} A^{2} \mu^{2} x^{2} . H(0)>0$ and $H^{\prime \prime}(x)<0$ imply there exists a unique $x_{0}>0$ such that $H\left(x_{0}\right)=0$. Subsequently, $P\left(x_{0}\right)$ has the sign of

$$
\begin{aligned}
& -b\left[4 a_{2}(1-m) \tau_{1}^{2}(1-\alpha)^{2} \mu^{2}+2\left(a_{1}-a_{2} \tau_{1}(1-\alpha)\right)^{2}+\right. \\
& \left.\quad+2\left(a_{1}-a_{2} \tau_{1}(1-\alpha)\right) \sqrt{\left(a_{1}-a_{2} \tau_{1}(1-\alpha)\right)^{2}+4 a_{2}(1-m) \tau_{1}^{2}(1-\alpha)^{2} \mu^{2}}\right]<0
\end{aligned}
$$

Because $x_{0}>0, P(0)>0$ and $P\left(x_{0}\right)<0$, we deduce that $x_{0}>x^{\star}$. Besides that, $H(0)>0$, $x^{\star}>0$ and $x^{\star}<x_{0}$ lead to $H\left(x^{\star}\right)=\frac{1}{1-\alpha} \frac{\partial P\left(x^{\star}\right)}{\partial \tau_{2}}>0$. Using $P\left(x^{\star}\right)=0$, the total differential formula of $P\left(x^{\star}\right)$ gives $\frac{\mathrm{d} x^{\star}}{\mathrm{d} \tau_{2}}=-\frac{\partial P\left(x^{\star}\right) / \partial \tau_{2}}{\partial P\left(x^{\star}\right) / \partial x}$. Because $\frac{\partial P\left(x^{\star}\right)}{\partial x}<0$ and $\frac{\partial P\left(x^{\star}\right)}{\partial \tau_{2}}>0$, thereby we have $\frac{\mathrm{d} x^{\star}}{\mathrm{d} \tau_{2}}>0$.

Regarding (ii), we can note that for a given level of productivity $A$ such that $A>A_{0}^{\star}$ $\left(>A_{1, \tau_{2}=0}\right)$, a rise in $\tau_{2}$ from $\tau_{2}=0$, raises $A_{1}$ as well. Since $A_{1, \tau_{2}}$ increases monotonically with $\tau_{2}$ and $\lim _{\tau_{2} \rightarrow 1-\tau_{1}} A_{1, \tau_{2}}=+\infty$, there exists a unique value $\hat{\tau}_{2}<1-\tau_{1}$ of $\tau_{2}$ such that $A_{1, \widehat{\tau_{2}}}=A$. In addition, for $\tau_{2}=\hat{\tau}_{2}$, we get $x_{1}=x_{2} \equiv x$. Now we just have to show that $x^{\star}>x$ for $\tau_{2}=\hat{\tau}_{2}$.

\footnotetext{
${ }^{12}$ See Appendix 5.
} 
$x^{\star}-x$ has the sign of ${ }^{13}$

$$
\begin{aligned}
& f\left(A_{1}\right) \equiv\left(a_{1}-a_{2}(1-\mu) \tau_{1}(1-\alpha)\right) E- \\
& \quad-2 a_{2} \mu \tau_{1}(1-\alpha) \sqrt{\left(\alpha+\tau_{2}(1-\alpha)\right)(1-m)\left(\alpha(b+1)+\tau_{2}(1-\alpha)\right) \mu \tau_{1}(1-\alpha)\left(a_{1}-a_{2}(1-\mu) \tau_{1}(1-\alpha)\right)}
\end{aligned}
$$

Hence,

$$
\begin{aligned}
& f\left(A_{1}\right)>\left(a_{1}-a_{2}(1-\mu) \tau_{1}(1-\alpha)\right) \times \\
& \times \sqrt{\left(\alpha+\tau_{2}(1-\alpha)\right)^{2}\left(a_{1}-a_{2} \tau_{1}(1-\alpha)\right)^{2}+4 a_{2}(1-m)\left(\alpha+\tau_{2}(1-\alpha)\right)\left(\alpha(b+1)+\tau_{2}(1-\alpha)\right) \tau_{1}^{2}(1-\alpha)^{2} \mu^{2}} \\
& \quad-2 a_{2} \mu \tau_{1}(1-\alpha) \sqrt{\left(\alpha+\tau_{2}(1-\alpha)\right)(1-m)\left(\alpha(b+1)+\tau_{2}(1-\alpha)\right) \mu \tau_{1}(1-\alpha)\left(a_{1}-a_{2}(1-\mu) \tau_{1}(1-\alpha)\right)}
\end{aligned}
$$

The term at the right side of the inequality is written as the difference of two positive expressions. To show that this term is positive, let us compare the square of these expressions. We have:

$$
\begin{aligned}
& \left(a_{1}-a_{2}(1-\mu) \tau_{1}(1-\alpha)\right)^{2}\left[\left(\alpha+\tau_{2}(1-\alpha)\right)\left(a_{1}-a_{2} \tau_{1}(1-\alpha)\right)^{2}+\right. \\
& \left.+4 a_{2}(1-m)\left(\alpha(b+1)+\tau_{2}(1-\alpha)\right) \tau_{1}^{2}(1-\alpha)^{2} \mu^{2}\right]- \\
& -4 a_{2}^{2} \mu^{2} \tau_{1}^{2}(1-\alpha)^{2}(1-m)\left(\alpha(b+1)+\tau_{2}(1-\alpha)\right) \mu \tau_{1}(1-\alpha)\left(a_{1}-a_{2}(1-\mu) \tau_{1}(1-\alpha)\right)> \\
& 4 a_{2}\left(a_{1}-a_{2}(1-\mu) \tau_{1}(1-\alpha)\right)^{2}(1-m)\left(\alpha(b+1)+\tau_{2}(1-\alpha)\right) \tau_{1}^{2}(1-\alpha)^{2} \mu^{2}- \\
& -4 a_{2}^{2} \mu^{2} \tau_{1}^{2}(1-\alpha)^{2}(1-m)\left(\alpha(b+1)+\tau_{2}(1-\alpha)\right) \mu \tau_{1}(1-\alpha)\left(a_{1}-a_{2}(1-\mu) \tau_{1}(1-\alpha)\right)= \\
& 4 a_{2}\left(a_{1}-a_{2}(1-\mu) \tau_{1}(1-\alpha)\right)(1-m)\left(\alpha(b+1)+\tau_{2}(1-\alpha)\right) \tau_{1}^{2}(1-\alpha)^{2} \mu^{2}\left[a_{1}-a_{2} \tau_{1}(1-\alpha)\right]>\mathbf{0}
\end{aligned}
$$

The lemma is proved.

\footnotetext{
${ }^{13} D_{0}, D_{1}$ and $D_{2}$ are defined in Appendix 1., whereas $E$ is in Appendix 6. By the way, $A_{1, \tau_{2}}$ is such that $D_{1}^{2}=4 D_{0} D_{2}$
} 


\section{References}

[1] Acemoglu, D., Jonhson, S., 2007. "Disease and Development: The effect of life expectancy on economic growth", Journal of Political Economy, 115, 925 - 985.

[2] Attanasio, O., Rohwedder, S., 2003. "Pension Wealth and Household Saving: Evidence from Pension Reforms in the United Kingdom", The American Economic Review, 93, 1499 - 1521.

[3] Attanasio, O., Brugiavini, A., 2003. "Social Security and Households' Saving", The Quarterly Journal of Economics, 118, 1075 - 1119.

[4] Barro, R., Sala-i-Martin, X., 1995. Economic Growth, Cambridge: The MIT Press.

[5] Bhatacharya, J., Qiao, X., 2007. "Public and private expenditures on health in a growth model", Journal of Economic Dynamics and Control, 31, 2519 - 2535.

[6] Blackburn, K., Cipriani, G.A., 2002. "A model of longevity, fertility and growth", Journal of Economic Dynamics and Control, 26, 187 - 204.

[7] Case, A., 2004. "Does Money Protect Health Status? Evidence from South African Pensions", Perspectives on the Economics of Aging, University of Chicago Press, june 2004.

[8] Cervelatti, M., Sunde, U., 2004. "Human Capital Formation, Life Expectancy and the Process of Development", The American Economic Review, 95, 1653 - 1672.

[9] Chakraborty, S., 2004. "Endogenous lifetime and economic growth", Journal of Economic Theory, 116, 119-137.

[10] Chakraborty, S., Das, M., 2005. "Mortality, Human Capital and Persistent Inequality", Journal of Economic Growth, 10, 159-192.

[11] De La Maisonneuve, C., Martins, J., 2013. "Public Spending on Health and Long-term Care: A new set of projections", OECD Economic Policy Papers, OECD Publishing, Paris.

[12] Direction de la sécurité sociale, 2015. "Les chiffres clés de la sécurité sociale 2014".

[13] Duflo, E., 2000. "Child Health and Household Resources in South Africa: Evidence from the Old Age Pension Program", The American Economic Review, 90, 393 - 398.

[14] Ebenstein, A., Fan, M., Greenstone, M., He, G., Yin, P., Zhou, M., 2015. "Growth, Pollution, and Life Expectancy: China from 1991-2012", BFI Working Paper Series no. 201503.

[15] Evans, M., Smith, K., 2005. "Do new health conditions support mortality-air pollution effects?", J. Environ. Econ. Manage, 50, 496-518. 
[16] Fogel, R.W., 1994. "Economic Growth, Population Theory, and Physiology: The Bearing of Long-Term Processes on the Making of Economic Policy", The American Economic Review, 84, 369 - 395.

[17] Huwart, J-Y., Verdier, L., 2012. "Quel impact la mondialisation a-t-elle sur l'environnement ?", La mondialisation économique : Origines et conséquences, Edition OCDE.

[18] Landrigan, P. et al., 2017. "The Lancet Commission on pollution and health", www.thelancet.com, Published online October 19, 2017, http:/ /dx.doi.org/10.1016/S0140-6736(17)32345-0?.

[19] Lundberg, O., Yngwe, M., Stjärne, M., Elstad, J., Ferrarini, T., Kangas, O., Norström, T., Palme, J., Fritzell, J., 2008. "The role of welfare state principles and generosity in social policy programmes for public health: an international comparative study", The Lancet, $372,1633-1640$.

[20] Marino, A., Morgan, D., Lorenzoni, L., James, C., 2017. "Future trends in health care expenditure: A modelling framework for cross-country forecasts", OECD Health Working Papers, OECD Publishing, Paris.

[21] National Oceanic and Atmospheric Administration, 2016. "Record annual increase of carbon dioxide observed at Mauna Loa for 2015", US Department of Commerce, accessed may 25, 2016, <http:/ / www.noaa.gov / record-annual-increase-carbon-dioxideobserved-mauna-loa-2015 $>$.

[22] OECD, 2013. Pensions at a Glance 2013: OECD and G20 Indicators, OECD Publishing.

[23] OECD, 2015. Pensions at a Glance 2015: OECD and G20 indicators, OECD Publishing, Paris.

[24] OECD, 2015. Health at a Glance 2015: OECD indicators, OECD Publishing, Paris.

[25] Raffin, N., Seegmuller, T., 2014. "Longevity, pollution and growth", Mathematical Social Sciences, 69, 22-33.

[26] Raffin, N., Seegmuller, T., 2017. "The cost of pollution on longevity, welfare and economic stability", Environmental and Resource Economics, 68, 683 - 704.

[27] Stieb, D., Judek, S., Brand, K., Burnett, R., Shin, H., 2015. "Approximations for estimating change in life expectancy attributable to air pollution in relation to multiple causes of death using a cause modified life table", Risk Analysis, 35, 22 - 33.

[28] Van Oort, F., Labanowski, J., Jongmans, T., Thiry, M., 2007. "Devenir des polluants métalliques dans les sols : révélateur d'impacts de l'activité humaine sur la pédogénèse ?", Etude et Gestion des Sols, 14, 287 - 303. 
[29] Varvarigos, D., 2010. "Environmental Degradation, Longevity, and the Dynamics of Economics Development", Environmental and Resource Economics, 46, 59 - 73.

[30] World Health Organization, 2006. Health risks of particulate matter from long-range transboundary air pollution.

[31] Zhang, J., Zhang, J., 2005. "The effect of life expectancy on fertility, saving, schooling and economic growth: Theory and evidence", The Scandinavian Journal of Economics, $107,45-66$. 